\title{
Users' brand page participation: a new construct to measure participation on social networking sites
}

Daniela Langaro* Business Research Unit (BRU-IUL), Department of Marketing, Operations and Management, Instituto Universitário de Lisboa (ISCTE-IUL), Av.a das Forças Armadas, 1649-026 Lisbon, Portugal Email: daniela.langaro@gmail.com

*Corresponding author

Maria de Fátima Salgueiro Business Research Unit (BRU-IUL), Department of Quantitative Methods for Business and Economics, Instituto Universitário de Lisboa (ISCTE-IUL), Av.a das Forças Armadas, 1649-026 Lisbon, Portugal Email: fatima.salgueiro@iscte.pt

Paulo Rita NOVA Information Management School (NOVA IMS), Universidade Nova de Lisboa, Campus de Campolide, 1070-312 Lisboa, Portugal Email: prita@novaims.unl.pt

This is the Accepted Author Manuscript of the article published by Inderscience International Journal of Internet Marketing and Advertising:

Langaro, D., Salgueiro, M. D. F., \& Rita, P. (2020). Users' brand page participation: A new construct to measure participation on social networking sites. International Journal of Internet Marketing and Advertising, 14(2), 135-151.

https://doi.org/10.1504/IJIMA.2020.107658 


\title{
USERS $^{\prime}$ BRAND PAGE PARTICIPATION: A NEW CONSTRUCT TO MEASURE PARTICIPATION ON SOCIAL NETWORKING SITES
}

\author{
$1^{\circ}$ author: Daniela Langaro PhD. \\ Business Research Unit (BRU- IUL) \\ Instituto Universitário de Lisboa (ISCTE-IUL) - Av. ${ }^{a}$ das Forças Armadas, 1649-026 \\ Lisbon, Portugal \\ daniela.langaro@gmail.com
}

Daniela Langaro is a visiting professor at ISCTE-IUL (Portugal), Vlerick Business School (Belgium) and Catholica Lisbon Business School (Portugal). Following her 15 years of experience in Consumer Packaged Goods and OTC industry, Langaro moved to academia in 2012. Her general research interests involve issues in internet marketing, social media, brand communications and brand management. She has published her research in scientific journals such as Journal of Marketing Communications, Journal of Event Management (accepted for publication) and Journal of Business Research.

\section{2nd. Author: Maria de Fátima Salgueiro}

Business Research Unit (BRU- IUL)

Department of quantitative methods for business and economics

Instituto Universitário de Lisboa (ISCTE-IUL) - Av. ${ }^{a}$ das Forças Armadas, 1649-026

Lisbon, Portugal

fatima.salgueiro@iscte.pt

Maria de Fátima Salgueiro is an Associate Professor of the Department of Quantitive Methods for Economics and Management at ISCTE-IUL, and Director of Business Research Unit (BRUIUL) of ISCTE-IUL, Lisbon, Portugal. Her research areas include structural equation models, graphical models and modelling longitudinal survey data. She has published her research in scientific journals such as Psychometrika, Biometrika, Multivariate Behavioural Reseach, Journal of Multivariate Analysis, Quality and Quantity; Journal of Official Statistics and Journal of Applied Statistics.

$3^{\circ}$ author: Paulo Rita PhD.

NOVA Information Management School (NOVA IMS)

Universidade Nova de Lisboa - Campus de Campolide 1070-312

Lisboa, Portugal

prita@novaims.unl.pt

Paulo Rita is Professor of Marketing, International Development Coordinator, Director of the Marketing Analytics Lab, Director of the Postgraduate programs in "Data Science for Marketing" and "Data Science for Hospitality and Tourism" at NOVA Information Management School (NOVA IMS), Universidade Nova de Lisboa, Portugal as well as Executive Committee member 
of the European Marketing Academy (EMAC). His research interests are focused on digital marketing / social media, consumer behavior / consumer neurosciences, and tourism marketing.

Acknowledgments: The authors are grateful for the financial support received from the Fundação de Ciência e Tecnologia (FCT) (SFRH / BD / 70672 / 2010).

\begin{abstract}
:
The increasing development of brand presence on Social Networking sites (SNS) requires new practices for monitoring the results of brands' efforts. The current research proposes that users' exposure to brand-related content by means of participating on brand pages is a key measure to be monitored. This proposition builds on previous studies which relate positive business consequences with users' exposure to brand communications. Despite the relevance of capturing users' participation on brand pages, so far very limited effort has been made to propose a construct for measuring it. Thus, three studies were implemented and a new construct was proposed and validated for internal consistency, unidimensionality and nomological validity.
\end{abstract}

\title{
Keywords:
}

Brand communications, Social Media, Social Networking Sites, Participation, Facebook, SNS, Construct development

\section{Introduction}

Social Networking Sites (SNS) have evolved into a relevant part of the internet experience, accounting for more than 2.7 billion active users worldwide on platforms like Facebook, Instagram and Twitter. This massive audience covers more than $70 \%$ of the total online population, which stay connected for more than 3 hours per day in many countries (Hootsuite, 2017). In response to these growing audiences, $90 \%$ of brands have launched their brand pages on SNS, adopting social media in their communication plans. 
Brand pages are embedded types of virtual brand communities (Sung et al. 2010; Zaglia 2013), where companies share their marketing content through regular posts. To join the brand page, users need to click the like button available on the brand page, with no requirement to supply extra personal information. From the moment users join the brand page, they start receiving branded content, targeted at captivating their participation, through the offering of functional, emotional and social benefits (Jahn and Kunz 2012; Mangold and Faulds 2009; Ham, Lee and Lee, 2014; Yilmaz and Enginkaya, 2015).

As the trend evolved, brand pages have started to represent an important share of brands' digital efforts, overtaking, in many cases, the attention originally dedicated to brands' websites. As the brands' interest in SNS increases, the need to monitor the results of brands' efforts also evolves. The current research proposes that users' exposure to brand-related content by means of participating on brand pages is a key measure to be monitored. With exposure resulting from the type of activities and frequency pattern adopted by users while participating on brand pages. This proposition builds on previous studies which relate positive consequences (e.g. purchase intentions, word-of-mouth and brand equity) with users' exposure to brand communications (e.g. Pham and Gammoh, 2015; Schivinski and Dabrowski, 2015; Mathur, 2018). Previous studies have argued that brand communications influence brand attitudes, reinforcing their strength and scope and, consequently, influence users' behaviors (Ham, Lee and Lee, 2014).

Despite the relevance of monitoring users' brand-related participation on brand pages on SNS, there has been very limited effort to propose a construct that captures participation. Indeed, authors of several previous studies have adopted varying measures but none reflect any effort with regard to developing a construct. The few studies that have addressed the problem of measuring users' brand-related participation focus on identifying observable measures available in brand pages and consolidating them (Hoffman and Fodor 2010). The main problem with this approach is that it only captures users' participation related to active behaviors, while the more predominant passive behaviors (e.g. reading posts) are ignored. So far, the only exception has been the study of Schivinski, Christodoulides and Dabrowski (2016) which proposed that participation is measured by means of three separate constructs which were dedicated to evaluating participation in the context of social media in general, and not in the specific context of brand pages' types of activities. 
The current study builds on this research gap, proposing a new construct to help brands monitor users' exposure to brand-related content on brand pages, by means of measuring their level of brand-related participation. In order to address this research problem, the current study is organized along three objectives based on Churchill's (1979) guidelines concerning the development of new constructs: i) specify the construct's domain; ii) generate a sample of items; iii) validate the measures statistically. In order to meet these objectives, three studies were implemented. Study 1 involved qualitative research aimed at exploring and specifying the construct's domain. Study 2 was aimed at validating the construct's internal consistency and unidimensionality by means of exploratory analysis. Study 3 follows a confirmatory approach aimed at validating the measures and testing their nomological validity using a different data-set.

\section{Literature Review}

Today's understanding of users' brand-related participation has evolved according to the development of media communications, as illustrated in Figure 1. In the context of traditional media, for example, participation is established within a dyad communication system (brand/user of traditional media) (Muniz and O'Guinn 2001), with brands creating contents to share with users and users consuming the content through reading and watching. In these contexts, user participation is captured by means of the number of TV sets tuned in to a particular program (as in the example of television audiences) and expressed by means of audiences' passive exposure to brand messages.

The development of virtual brand communities has challenged this traditional communication flow, with the tools for interactivity enlarging the scope of user participation to encompass a triad communication system (brand/users of virtual brand community/other users), established among brand admirers (Muniz and O'Guinn 2001). In these contexts, consumers and brands collectively create value through participation. Users are expected to participate not only by consuming content (e.g. reading or watching), but also by contributing with their opinion and creating content.

Studies in virtual brand communities are unequivocal with respect to the importance of succeeding in conquering user participation, but differ as to which theoretical approach to adopt to measure it. Adjei et al. (2010) for example, have approached participation from the perspective of its quality, defined by the relevance, frequency, length and recency of comments. Other authors approach participation either as a measure of the 
perceived social support that users get from the community (Woisetschläger et al. 2008; Casaló et al 2008), or as an expression of users' intentions towards the community, measured through their future intention to participate (Algesheimer et al. 2005; Bagozzi and Dholakia 2006).

Differently from virtual brand communities, where brands are at the center of the community and unite brand admirers, brand pages on SNS are embedded in users' own social groups (Jahn and Kuntz 2012). This implies a change in the focus (the user, instead of the brand) and scope of participants, as users' own social groups are also exposed to users' activities regarding brand pages. As a result, the communication flow is expanded to a quadriad communication system (Brand/Users of brand page/ Users' friends on SNS/ Other users of brand pages), with users' own social groups integrating the context.

\section{INSERT FIGURE 1 HERE}

In the context of Social Media, despite the differences across studies, there is some consensus on measuring user participation as an expression of usage patterns, expressed through types of activities and frequency of participation (Pagani et al. 2011; Shao, 2009; De Vries et al 2012; Muntinga et al. 2011; Zhou, 2011). These studies capture participation based on functionalities available on SNS, using measures like: the number of times users visit and interact with others in brand-related social media (Zhou, 2011; Sung et al., 2010); the number of 'likes' and 'comments' (Langaro, Rita and Salgueiro, 2015, De Vries et al., 2012; Cvirjik and Michahelles, 2013; Pagani et al., 2011; Pagani and Malacarne, 2017); frequency of posting (Langaro, Rita and Salgueiro, 2015, De Vries et al, 2012; Pagani et al., 2017; Pagani et al., 2011; Pagani and Malacarne, 2017); and viewing and reading content (Jahn and Kunz, 2012; Pagani and Malacarne, 2017). In general, these studies do not discuss the measures selected, nor do they offer a conceptual understanding for the criteria used.

In that sense, the contribution of Muntinga et al. (2011) was of great importance as the authors proposed, based on qualitative research, that user participation on social media is organized within three typologies, namely: consuming, contributing and creating content. Consuming content is associated with types of activities present in traditional media, with users reading, viewing and watching content that is published by brands and other users, with no active interaction taking place. Contributing implies that users interact with the 
content expressing their opinion by means of activities like giving 'likes' and writing 'comments'. Meanwhile, creating involves users activities related to generating content that is shared with their own 'friends' on SNS. The authors propose that users tend to adopt the various types of participation interchangeably, depending on the type of gratification expected.

The approach proposed by Muntinga et al. (2011) has provided conceptual guidance to the current study as presented in the methodology and results.

\section{Methodology}

Bearing in mind the research objectives proposed, the current research has followed the phases proposed in Churchill (1979). In total, three studies were implemented. In study 1, a qualitative approach was used to specify the construct's domain. In study 2, measures were proposed and validated in an exploratory data analysis for their internal consistency and unidimensionality. In study 3, a confirmatory data analysis was performed with measures being validated in a new data-set and tested for their nomological validity. The studies focused on Facebook given its relevance in the context of total social networking sites' audiences worldwide. Data collection was implemented in Portugal, which was chosen as the research market based on the outperforming penetration of Facebook users in the total online population ( $80 \%$ in Portugal versus $50 \%$ in Europe) (Internet World Stats, 2017).

\subsection{Qualitative analysis}

\section{- Study 1}

The main objectives were: to further investigate the construct's domain in view of the embeddedness of brand pages in users' social networks; to explore the typologies of users' participation and activities; and, based on the literature review and learning, define the construct of users' brand page participation. This involved qualitative research conducted with Facebook users, by means of 10 individual in-depth interviews. The interviewees were recruited through the snow-ball method, with initial respondents referring others. The criteria for selection were that interviewees should be regular users of Facebook and fans of brand pages. The interviews were semi-structured, being 
conducted in-person and through online platforms (Skype), audio-recorded lasting between 45 and 60 minutes. Each interview was transcribed and the typed transcripts were analyzed using open coding, followed by thematic coding around categories corresponding to the research questions.

\section{- Results Study 1}

In order to address the objectives proposed for study 1, the authors organized the findings in two topics, which are presented and briefly illustrated with transcripts taken from the interviews. The first topic is related to users' perspectives on brand pages in view of their embeddedness in users' own social networks. The second topic explores the typologies of activities and associated meanings.

\section{Users and their perspective on brand pages:}

Interviewees revealed that as their level of Facebook usage evolved, it gradually developed into a personal and multifaceted communication platform where they managed their relationships, social identity expression and increasingly addressed their needs for self-enhancement, entertainment, information, remuneration and consumption (Papacharissi and Mendelson 2011).

The following transcript illustrates this:

'I use Facebook not only as a personal home page, but also as a network that integrates friends, shops and small businesses. In Facebook, besides being able to get information from a friend who was on a trip and posted a photo, I can also get information from shops offering discounts, from people who sell handcrafted objects, etc.' (woman, 33 y/o).

Within this multifaceted communication scope, interviewees reveal they combine their private and professional, intimate and distant connections into one social audience

The following transcript illustrates this:

' I mainly use Facebook for personal reasons. Despite that, I also use it for professional reasons ... I have 312 friends. I access it every day and I am connected all the time. I see pictures, read newspapers, and check conferences .... I have reunited on Facebook with friends that I had not seen for a long time and I keep contact with colleagues from work' (woman, $31 \mathrm{y} / \mathrm{o}$ ). 
These findings extend the understanding of users's social groups beyond friends and acquaintances, and position brand pages as distant participants which are embedded in users' social audiences and compete for attention with their friends, family, groups of interest, professional contacts and other brands. This distant type of relationship sets the context in which users' brand page participation occurs, with brand pages being positioned by users as participants with less importance in relation to others. Beyond that, while discussing their participation, users associate it to the relevance of the content offered by the brand page and to the level of social exposure intended while participating (e.g: giving a 'like' to a post). These aspects are further explored in the following paragraphs.

\section{Users and their types of participation on brand pages:}

After users join brands on their brand pages, they are targeted with content meant to evoke their participation, through consuming, contributing or creating content (Muntinga et al., 2011). During the interviews, users associate their participation to the relevance of the content offered by the brand page and gratifications expected (e.g. socialization, self-enhancement, entertainment, information). These findings are supported by previous studies (Jahn and Kunz 2012; Ham, Lee and Lee, 2014; Yilmaz and Enginkaya, 2015) and reinforce the importance of value being extracted from users' participation (Tan et al., 2012).

Moreover, the current study extends previous findings, revealing that users' own social networks have a key influence on the type of activity adopted, with some activities being inhibited by the kind of social exposure associated with them and others being triggered by that. In both cases, the activities related to contributing (e.g. giving 'likes' or writing 'comments' to posts) and creating (e.g. creating new content) are left to the users' judgement as to their suitability, fit and value in relation not only to themselves, but also to their own social audiences and the image that they intend to convey.

As such, the findings reveal that while contributing interviewees position their 'likes' as a social sign of approval and endorsement of contents, they are nevertheless aware of the social implications potentially associated, as illustrated in the following transcript:

'What sort of posts deserve like? It has to be something that I like, to celebrate a victory, some product that you like because you think it is very 
good, also to support something cool that someone is doing and deserves to be shown' (woman, 43 y/o).

In addition, the activities related to commenting are somehow associated with users' intentions to further contribute to the brand and other users in the brand pages. This activity is not often present in the transcripts, which might relate to users' distant relationship and predominant lack of interest in establishing connections with other members of brand pages (Zaglia et al. 2013). Furthermore, commenting is also associated with the post format, as some posts use language expressions that invite users to interact whereas others do not.

Finally, activities related to sharing content are presented by interviewees as functionality meant for recommending and creating interactions with users' own social networks. As such, users position their sharing activities as part of their efforts to create conversations by leveraging on content that was originally generated by the brand. This perspective differs from previous findings as sharing is positioned among creating, rather than contributing types of brand-related activities (Muntinga et al., 2011).

Having discussed contributing and creating brand-related types of activities, it would appear that consuming content through reading posts and accessing links is the way that consumers most often interact with brand pages, by means of enjoying the benefits of participation without using it as a way to socialize. Thus users' consciousness of the impact of participation on their self-exposure seems to inhibit their behaviours.

Users' concerns for the implications of participation on privacy and self-image are often mentioned as inhibitors to socializing the content that users' consume. This finding is supported by previous studies which position privacy (Tan et al, 2012; Pagani, and Malacarne, 2017) and self-expressiveness as influencing factors in users' willingness to participate. As illustrated:

'I usually do not click like to posts because I want to keep my privacy. I find it strange that brands publish things for everyone and that anyone can get to know who I am' (woman, 40 y/o);

In conclusion, users' 'likes', 'comments' and 'shares' are contextualized by the interviewees as functionalities meant for getting exposure, voicing their opinion and to socialize, as suggested in previous social media studies (Shao, 2009). Moreover, users differentiate their 'likes' and 'comments' from their 'shares', as the latter represent users' 
efforts to create their own interactions with their networks. On the other hand, consuming content seems to occur more independently from social implications.

The findings help to support the quadriad type of communication system (see Figure 1) occurring on SNS, with users' own networks influencing the type of activity and frequency of users' brand page participation. Furthermore, the results also endorse the understanding that users most often associate their types of activities on brand pages to the contents' characteristics and their own expectations to socialize (Muntinga's et al., 2011). Finally, the study validates the general typologies associated with participation using measures related to consuming, contributing and creating content, thus contributing towards capturing the completeness of the construct domain in its different nuances and meanings.

Thus, once the embeddedness of brand pages in users's social audiences and the impact on the types of participation had been explored, the construct of users' brand page participation was conceptualized. Literature review and findings from qualitative research were used to posit the following definition:

Users' brand page participation is a construct that captures users' brand-related activities regarding contents that are created by brands or other users on brand pages on social networking sites. The construct involves three types of activities (consuming, contributing and creating) which are expressed in relation to actions performed by users on the brand page and measured in relation to the frequency with which they are performed.

The construct builds on the perspective of brand pages as communication channels intended for brands to impact their audiences. As such, the conceptualization proposed captures the extent of users' exposure to brand-related content created on brand pages on SNS.

\subsection{Quantitative analysis}

\section{- Study 2}

The aim of conducting study 2 was to assess the reliability and unidimensionality of the proposed construct in an exploratory data analysis. This consisted of an online survey 
with the sample being collected from among Facebook users who were members of brand pages for consumer product goods. The criteria for selection of brands were based on the size of the audience and level of users' engagement. The final sample comprised brands from personal care and beauty segments due to that category's high level of engagement.

Respondents were recruited through a convenience sampling method, via targeted Facebook ads. A banner was positioned next to the users' newsfeed, inviting them to participate in an online study, available through a direct link to the Qualtrics Research Platform. The items identified represent the most prominent scope of activities related to consuming, contributing and creating content, as identified in the literature and in qualitative research (see Table 1). The items were measured on a seven-point Likert scale of frequency of use (1=never; $4=$ sometimes; $7=$ always).

\section{INSERT TABLE 1 HERE}

\section{- Results Study 2}

A total of 203 valid responses were obtained. With regard to the sample characteristics, participants were between 18 and 54 years old, with a median age of 18$24(58 \%)$. Regarding occupation, the sample was mixed with $40 \%$ being students. The majority of the participants visit Facebook on a daily basis, 57\% spend less than two hours.

At this phase, the construct of users' brand page participation was assessed for unidimensionality using principal components analysis in IBM SPSS V.24. Extraction was based on the existence of eigenvalues larger than 1 , with one component being obtained. Furthermore, it was required that all factor loadings were larger than 0.5 , and that a considerable amount of total explained variance was obtained. All items presented standardized factor loadings above 0.50 and a total variance explained of $61 \%$ was obtained.

Additionally, reliability was accessed using Cronbach's Alpha, with results above the minimum required level being obtained for reliability (Nunnally and Bernstein, 1994) with a coefficient of 0.86 . Final results are presented in Table 2.

\section{INSERT TABLE 2 HERE}




\section{- Study 3}

Study 3 consisted of an online survey aimed at validating the proposed construct in a new data-set for its coefficient of reliability, unidimensionality, model-data fit and nomological validity.

Two separate procedures were implemented. In the first phase, confirmatory factor analysis using LISREL 8.80 (Jöreskog and Sörbom, 2006) was used to evaluate the construct's model-data fit by means of a measurement model estimation, with results also being used to evaluate the construct's coefficient of reliability (CR) and average variance extracted (AVE).

In a second phase, to evaluate the construct's nomological validity, a new measurement model was estimated with the objective being to validate whether the construct behaved as expected in relation to its nomological network. Therefore, at this phase, study 3 explores the psychometric properties of the scale in view of two important constructs - brand attitude and purchase intention - that capture the effects of consumers' exposure to brand-related content while participating. Consumers' engagement with brand-related communications is expected to lead to increased brand knowledge and, consequently, to impact consumers' responses (Keller, 1993). This effect is well supported in previous social media studies with consumers' exposure to brand communications being positively correlated with effects on brand attitude, an important dimension of brand knowledge (Langaro et al., 2015; Bruhn et al., 2012; Schivinski and Dabrowski, 2015). Moreover, internet and social media studies reveal that as users are impacted in their brand attitude, their responses regarding future purchase intentions are also affected (Adjei et al. ,2010; Bagozzi and Dholakia, 2006; Algesheimer et al., 2005; Shang et al., 2006).

Thus, in view of previous findings, it is expected that the two constructs are positively correlated with users' brand page participation.

Study 3 has followed the general sampling procedures adopted in study 2. The measures used were extracted from study 2. Brand attitude was measured using 5 items adapted from Spears and Sign (2004) capturing users' evaluations towards the brand. Purchase intentions were measured by three items adapted from Sirdeshmukh et al (2002) and Yoo and Donthu (2001). Table 3 shows the specific items. 


\section{- Results of Study 3}

A total of 575 valid responses were obtained, with the structure of the sample closely matching study 2.

In the first phase of analysis, confirmatory factor analysis was used to validate the proposed construct. The measurement model was calculated using a robust maximum likelihood estimator, previously implemented in Lisrel 8.8 (Jöreskog and Sörbom, 2006). The obtained measures of fit suggest there is an acceptable model-data fit (Schumacker and Lomax, 2010), as presented in Figure 2 with the following results: $\chi 2=61.5$; $\mathrm{df}=9$; p-value=0.0000; RMSEA=0.10; CFI=0.98; NFI=0.98; IFI=0.98; RFI=0.96; GF=0.95. There is also evidence for reliability and convergence of the proposed construct, with a good coefficient of reliability (0.87), and average variance extracted (AVE) being obtained (0.54) (Hair, et al, 2009; Fornell and Larker, 1981).

\section{INSERT FIGURE 2 HERE}

In the second phase of analysis, the nomological validity of the construct proposed was evaluated. All latent variables (users' brand page participation, purchase intention and brand attitude) were included in a measurement model with a new confirmatory factor analysis being run. The results obtained evidence a good model-data fit (CFA: $\chi 2=156.4$; $\mathrm{df}=74 ; \mathrm{p}$-value=0.0000; RMSEA=0.04; $\mathrm{CFI}=0.98 ; \mathrm{NFI}=0.99 ; \mathrm{IFI}=0.99 ; \mathrm{RFI}=0.99$; $\mathrm{GF}=0.92$ ). The coefficient of reliability for each scale ranged from 0.84 to 0.96 . These values exceeded the threshold of 0.7 , indicating the internal consistency of the scales. All factor loadings were significant and varied from 0.62 to 0.93 (as in Table 3). The average variance extracted obtained were between 0.54 to 0.82 .

Furthermore, the outcomes of the correlation analysis across users' brand page participation, brand attitude and purchase intention ranged from 0.52 to 0.81 with a tvalue between 8.9 and 18.20 ( $\mathrm{p}<0.001$; see Table 4, first two columns).

In order to further validate the results regarding nomological validity, the original sample was divided into two random sub-samples $(\mathrm{n} 1=296 ; \mathrm{n} 2=279)$. The proposed measurement model was fitted separately to each of the samples and correlation coefficients among users 'brand page participation, attitude and purchase intention were computed for each sub-sample. Correlation values among the three constructs remain stable as depicted in Table 4 (last two columns). 
Results from both rounds of correlation analysis validate the new construct proposed for its nomological validity, as it behaves as expected in relation to other constructs in its nomological network.

\section{INSERT TABLE 3 AND TABLE 4 HERE}

\section{Conclusions}

\subsection{Discussion and theoretical contributions}

In response to the development of SNS, most brands launched their brand pages and started integrating them in their communication efforts. As long as brand interests towards SNS continue to evolve, the need for monitoring their results also increases. In the current research users' exposure to brand-related content on brand pages is accepted as a key measure to be monitored, with exposure resulting from the type of activities and pattern of frequency adopted by users while participating on the brand page. This proposition was built on previous studies which relate positive business consequences (e.g. purchase intentions, word-of-mouth, brand equity) to users' exposure to brand communications (e.g. Schivinski and Dabrowski, 2015; Pham and Gammoh, 2015; Mathur, 2018). These consequences are driven by the relational effects between users' exposure to brand communications, brand attitude and intentions towards the brand, with users behaving in accordance with their attitudes (eg. Ham, Lee and Lee, 2014).

Despite the relevance of monitoring users' brand-related participation on brand pages on SNS, the efforts made to propose a construct that captures participation are very limited, with authors adopting measures that vary among studies and do not reflect the type of efforts that a construct development requires. The current study builds on this research gap, proposing a new construct to help brands monitor users' exposure to brandrelated content on brand pages through measuring their level of brand-related participation. The study was organized around three objectives. First, the construct's domain was specified; second the initial items were identified; third the construct was evaluated for reliability, unidimensionality and nomological validity. Three research studies were implemented. 
In study 1, qualitative research was implemented, with findings positioning brand pages as a distant participant in users' network of 'friends' competing for attention with users' private and professional relations. The findings support the existence of the three types of participation (consuming, contributing and creating), which are adopted interchangeably depending on the relevance of the content that users are exposed to, and the level of social exposure intended. In that sense, the current study makes a new contribution by revealing that users' consciousness of their own social networks influence the type of participation they adopt. With the level of social exposure filtering users' activities and frequency patterns related to contributing and creating content, the way consumers most often enjoy brand-related content would appear to be through consuming content.

Thus, the construct domain is conceptualized as a construct that captures users' brandrelated activities regarding contents that are created by brands or other users in brand pages on social networking sites. The construct involves three types of activities (consuming, contributing and creating) which are expressed in relation to actions performed by users on the brand page and measured in relation to the frequency with which they are performed. This conceptualization addresses the idea of brand pages as a communication channel intended for brands to impact their audiences by means of user exposure to brand-related contents.

In study 2, a group of six items were identified, reflecting the three types of activities associated with user participation. The items were evaluated in an exploratory data analysis and the construct was validated for reliability and unidimensionality, with one construct being extracted. In study 3 , the confirmatory data analysis further validated the construct based on its coefficient of reliability and average variance extracted. At this stage, the construct was also analyzed for the goodness-of fit of its measurement model, with a good fit obtained.

In the final stage of analysis, we evaluated whether the new construct behaved as expected in relation to its nomological network. Three latent variables (users' brand page participation; purchase intention and brand attitude) were included in a new measurement model, which evaluated the correlations between constructs, obtaining significant effects The correlation analysis was run twice. First the full sample of study 3 was considered and a Global Confirmatory factor analysis was implemented. Then the sample was split into two random sub-samples to further validate correlation results. Thus, nomological validity of the proposed construct is confirmed. 
Hence, as the current study builds on the need to identify and propose a construct which is able to help monitor brands' efforts on SNS, its most important theoretical contribution is the proposition and validation of a new construct - users' brand page participation. When applying the new construct, studies may find various advantages in using a standardized approach associated to the reliability and validity of their models and comparability between studies. This contribution is especially relevant considering that previous studies used measures that vary among each other and do not reflect the efforts required while developing and proposing a new construct.

\subsection{Implications for practice}

The increasing adoption of SNS requires that brands implement mechanisms for monitoring their efforts. Hence, the construct proposed suggests that managers monitor their users' exposure to brand-related communications by means of capturing users' participation on brand pages, with users' participation resulting from the types of activities (consuming, contributing and creating) and the frequency pattern adopted by users while participating on brand pages.

In that sense, the current study proposes a construct comprising six items and suggests that these be used when planning and evaluating brands' activities on SNS. Regarding its future implementation, we recommend that brands create research panel mechanisms capable of regularly monitoring users' brand page participation, and that comparisons with other competitors be considered in order to establish action standards and objectives.

\subsection{Limitations and future studies}

Although the current research makes a significant contribution to the theory and practice associated with social networking sites, the findings are subject to limitations. Future studies could profit from addressing these limitations, which are mentioned below.

The current study has focused on a specific geography (Portugal) and brand category (beauty and personal care). Although both choices were well supported by the high level of penetration of SNS, brand activity and level of user engagement, future studies could seek to expand the scope of analysis.

Moreover, the study focuses on Facebook, based on its relevance among social networking sites and commonalities with other platforms in terms of types of activities 
associated with user participation. Future studies could involve other platforms (e.g. Instagram).

Finally, while evaluating the nomological network, future studies could extend beyond the effects on brand attitude and purchase intentions, to considering users' willingness to further evolve in their relationship with the brand, through their involvement in activities related to other conative brand engagement outputs (as for e.g. Brand advocacy and cocreation) and with privacy concerns, social exposure and content relevance being considered as influencing aspects.

\section{References}

Adjei, M.T., Noble, S.M. and Noble, C.H., (2010) 'The influence of C2C communications in online brand communities on customer purchase behavior', Journal of the Academy of Marketing Science, Vol. 38 No.5, pp. 634-653.

Algesheimer, R., Dholakia, U.M. and Herrmann, A.,(2005) 'The social influence of brand community: Evidence from European car clubs', Journal of Marketing, pp. 19-34.

Bagozzi, R. P. And Dholakia, U.M., (2006) 'Antecedents and purchase consequences of customer participation in small group brand communities', International Journal of Research in Marketing, Vol. 23 No.1, pp. 45-61.

Casaló, L.V., Flavián, C. And Guinal'iu, M., (2008) 'Promoting consumer's participation in virtual brand communities: A new paradigm in branding strategy', Journal of Marketing Communications, Vol. 14 No.1, pp.19-36.

Churchill Jr, G.A., (1979), 'A paradigm for developing better measures of marketing constructs`, Journal of Marketing Research, pp. 64-73.

Dholakia, U.M., Bagozzi, R. P. And Pearo, L.K.,(2004) 'A social influence model of consumer participation in network-and small-group-based virtual communities', International Journal of Research in Marketing, Vol. 21 No.3, pp. 241-263.

Djomba (2016) fbrank - Facebook Ranking in Portugal, Retrieved 1 November (2016), from: http://www.fbrankpt.com/index.php/marcas

Ellison, N.B., Steinfield, C. And Lampe, C., (2007) 'The benefits of Facebook “friends:" Social capital and college students' use of online social network sites', Journal of Computer-Mediated Communication, Vo. 12 No. 4, pp. 1143-1168. 
Facebook (2017) Photos, Retrieved June 15 ${ }^{\text {th }}$ (2017), from: https://www.facebook.com/facebook/photos_stream

Ham, C. D., Lee, J., and Lee, H. S. (2014) 'Understanding consumers' creating behaviour in social media: an application of uses and gratifications and the theory of reasoned action', International Journal of Internet Marketing and Advertising, Vol. 8 No.4, pp. 241-263.

Hoffman, D.L. and Fodor, M., (2010) 'Can you measure the ROI of your social media marketing', MIT Sloan Management Review, Vo. 52 No.1, pp. 41-49.

Jahn, B. and Kunz, W., (2012) 'How to transform consumers into fans of your brand', Journal of Service Management, Vol. 23 No.3, pp. 344-361.

Yoo, B. And Donthu, N., (2001), 'Developing and validating a multidimensional consumer-based brand equity scale', Journal of Business Research, Vol. 52 No.1, pp. 114.

Langaro, D., Rita, P., and de Salgueiro, M. F. (2018) 'Do social networking sites contribute for building brands? Evaluating the impact of users' participation on brand awareness and brand attitude', Journal of Marketing Communications, Vol. 24 No.2, pp.146-168.

Lampe, C., Ellison, N. and Steinfield, C., (2006) 'A Face (book) in the crowd: Social searching vs. Social browsing', Proceedings of the 20th anniversary conference on Computer supported cooperative work, pp.167-170.

Madupu, V. and Cooley, D.O., (2010) 'Antecedents and consequences of online brand community participation: a conceptual framework', Journal of Internet Commerce, Vol. 9 No.2, pp. 127-147.

Mangold, W.G. and Faulds, D.J., (2009) 'Social media: The new hybrid element of the promotion mix', Business Horizons, Vol. 52 No.4, pp. 357-365.

Mathur, M. (2018) 'Quantifying the long-term effect of social media', International Journal of Internet Marketing and Advertising, Vol. 12 No.1, pp. 19-39.

Mathwick, C., (2002) 'Understanding the online consumer: a typology of online relational norms and behavior', Journal of Interactive Marketing, Vol. 16 No.1, pp. 4055.

Muniz Jr, A.M. and o'guinn, T.C., (2001) 'Brand community', Journal of Consumer Research, Vo. 27 No.4, pp. 412-432.

Muntinga, D.G., Moorman, M. And Smit, E.G., (2011) 'Introducing cobras', International Journal of Advertising, Vol. 30 No.1, pp. 13-46. 
Nunnally, J.C. and I.H. Bernstein, (1994) Psychometric Theory. Mcgraw-Hill, New York.

Pagani, M., Hofacker, C.F. and Goldsmith, R.E., (2011) 'The influence of personality on active and passive use of social networking sites', Psychology and Marketing, Vol. 28 No.5, pp. 441-456.

Pagani, M., and Malacarne, G. (2017) 'Experiential engagement and active vs. passive behavior in mobile location-based social networks: the moderating role of privacy', Journal of Interactive Marketing, Vol. 37, pp.133-148.

Papacharissi, Z. and Mendelson, A., (2011) '12 Toward a new (er) sociability: uses, gratifications and social capital on Facebook', Media perspectives for the 21st century, pp.212.

Pham, P. H. M., and Gammoh, B. S. (2015) 'Characteristics of social-media marketing strategy and customer-based brand equity outcomes: A conceptual model', International Journal of Internet Marketing and Advertising, Vol. 9 No.4, pp. 321.

Schau, H.J., Muniz Jr, A.M. and Arnould, E.J., (2009) 'How brand community practices create value', Journal of Marketing, Vol. 73 No.5, pp. 30-51.

Shao, G.,(2009) Understanding the appeal of user-generated media: a uses and gratification perspective', Internet Research, Vol. 19 No.1, pp.7-25.

Schivinski, B., Christodoulides, G., and Dabrowski, D. (2016) 'Measuring consumers' engagement with brand-related social-media content: Development and validation of a scale that identifies levels of social-media engagement with brands', Journal of Advertising Research, Vol. 56 No.1, pp. 64-80.

Sirdeshmukh, D., Singh, J. and Sabol, B.,(2002) 'Consumer trust, value, and loyalty in relational exchanges', The Journal of Marketing, pp. 15-37.

Spears, N., and S. N. Singh. (2004) 'Measuring Attitude Toward the Brand and Purchase Intentions', Journal of Current Issues and Research in Advertising, Vol. 26 No. 2, pp. 53-66.

Sung Y., Kim Y., Kwon and Moon J., (2010) 'An Explorative Study of Korean Consumer Participation in Virtual Brand Communities in Social Network Sites', Journal of Global Marketing, Vol. 23 No. 5, pp. 430-445.

De Vries, L., Gensler, S. and Leeflang, P.S., (2012) 'Popularity of Brand Posts on Brand Fan Pages: An Investigation of the Effects of Social Media Marketing', Journal of Interactive Marketing, Vol. 26, pp. 83-91. 
Wallace, E., Buil, I. and De Chernatony, L., (2012) 'Facebook "friendship" and brand advocacy', Journal of Brand Management, Vol. 20 No.2, pp. 128-146.

Woisetschläger, D.M., Hartleb, V. and Blut, M., (2008) 'How to make brand communities work: antecedents and consequences of consumer participation', Journal of Relationship Marketing, Vol. 7 No.3, pp. 237-256.

Worldometers, (2017). Sociedade e Meios de Comunicação, Retrieved May (2017), from: http://www.worldometers.info/pt/

Yilmaz, H., and Enginkaya, E. (2015) 'Brand followers: Motivations and attitudes of consumers to follow brands in social media', International Journal of Internet Marketing and Advertising, Vol. 9 No.1, pp. 3-20.

Zaglia, M.E., (2013). Brand communities embedded in social networks. Journal of Business Research, Vol. 66, pp. 216-223.

TABLE 1: Items considered and source

\begin{tabular}{|l|l|}
\hline \multicolumn{1}{|c|}{ Items } & \multicolumn{1}{c|}{ Source } \\
\hline Read brand posts posted on the brand page & Muntinga, Moorman and Smit 2011 \\
Click 'like' to posts, photos or videos posted on the brand page & de Vries, Gensler and Leeflang 2012; \\
Acess video and music links posted on the brand page & Muntinga Moorman and Smit 2011 \\
Comment on the posts published on the brand page & de Vries, Gensler and Leeflang 2012; \\
Share with friends the content published on the brand page & de Vries, Gensler and Leeflang 2012; \\
Read others' comments to the brand posts & Identified in Study 1 \\
\hline
\end{tabular}

TABLE 2: Results from preliminary Exploratory Factor Analysis and Cronbach Alpha

\begin{tabular}{|c|c|c|c|}
\hline Construct & Factor Loadings & Cronbach alpha & Cronbach's if item deleted \\
\hline \multicolumn{4}{|c|}{0.87} \\
\hline Read brand posts posted on the brand page & 0.73 & & 0.86 \\
\hline Click 'like' to posts, photos or videos posted on the brand page & 0.84 & & 0.84 \\
\hline Acess video and music links posted on the brand page & 0.78 & & 0.85 \\
\hline Comment on the posts published on the brand page & 0.79 & & 0.84 \\
\hline Share with friends the content published on the brand page & 0.81 & & 0.84 \\
\hline Read other's comments to the brand posts & 0.75 & & 0.86 \\
\hline
\end{tabular}


TABLE 3: Factor loadings obtained in Confirmatory Factor Analysis, Coeficient of Reliability and Average Variance Extracted

\begin{tabular}{|c|c|c|c|}
\hline & Standardized factor loading & $\mathrm{CR}$ & AVE \\
\hline Users'́ Brand Page Participation & & 0.88 & 0.54 \\
\hline Read brand posts posted on the brand page & 0.62 & & \\
\hline Click 'like' to posts, photos or videos posted on the brand page & 0.67 & & \\
\hline Acess video and music links posted on the brand page & 0.72 & & \\
\hline Comment on the posts published on the brand page & 0.86 & & \\
\hline Share with friends the content published on the brand page & 0.81 & & \\
\hline Read others' comments to the brand posts & 0.71 & & \\
\hline Brand Attitude & & 0.96 & 0.82 \\
\hline More favorabe & 0.91 & & \\
\hline More appealing & 0.91 & & \\
\hline Better & 0.92 & & \\
\hline More pleasant & 0.87 & & \\
\hline More likable & 0.93 & & \\
\hline \multicolumn{4}{|l|}{ Purchase intention } \\
\hline It will easily become my main brand in its product category & 0.85 & 0.84 & 0.64 \\
\hline I will buy it frequently & 0.86 & & \\
\hline \multicolumn{4}{|l|}{ If the brnad is out-of-stock in the shop I usually buy from, I } \\
\hline will look for it elsewhare & 0.68 & & \\
\hline
\end{tabular}

Brand attitude and Purchase intentions were measured in a seven-point scale of agreement (1=completely disagree; $4=$ neither agree, nor disagree; $7=$ completely agree). Users ${ }^{\prime}$ brand page participation was measured in a seven-point scale of frequency $(1=$ never; $4=$ sometimes=; $7=$ always $)$.

TABLE 4: Correlation Analysis Outcomes across users'́ brand page participation (BPP), brand attitude and purchase intentions

\begin{tabular}{|c|c|c|c|c|}
\hline & \multicolumn{2}{|c|}{ Total Sample } & Sample $1(\mathrm{n} 1=296)$ & Sample $2(\mathrm{n} 2=279)$ \\
\hline Correlated factors & $\begin{array}{c}\text { Correlation } \\
\text { Coeff. }\end{array}$ & T-Value & \begin{tabular}{|c|c|} 
Correlation \\
Coeff.
\end{tabular} & $\begin{array}{c}\text { Correlation } \\
\text { Coeff. }\end{array}$ \\
\hline BPP and Brand attitude & 0.52 & 8.9 & 0.53 & 0.49 \\
\hline BPP and Purchase intentions & 0.59 & 10.15 & 0.64 & 0.54 \\
\hline Brand attitude and Purchase intention & 0.81 & 18.2 & 0.81 & 0.80 \\
\hline
\end{tabular}

Global CFA Model: $\chi 2=156.4$;f=74;RMSEA=0.04; CFI=0.98; NFI=0.99; IFI:0.99,GFI=0.92;

Estimator: Robust maximum-likelihood; $n=575$; all standardized coefficients are significant at the $5 \%$ level 
FIGURE 1: Three different communication systems - from traditional media to social networking sites

\section{Traditional Media: Dyad}

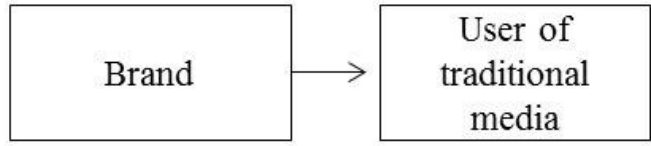

Virtual Brand Community (VBC): Tryad

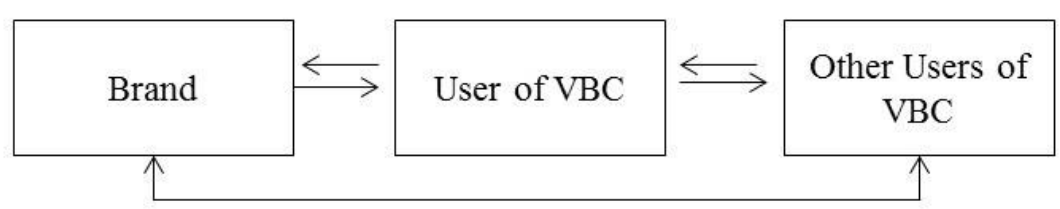

Brand pages at Social Networking Sites (SNS): Quadriad

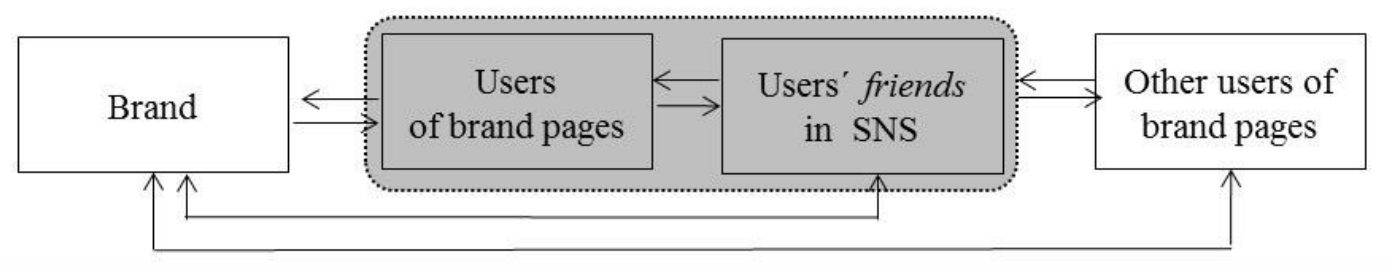

Elaborated by the authors based on literature review

FIGURE 2: Confirmatory Factor Analysis for the new construct

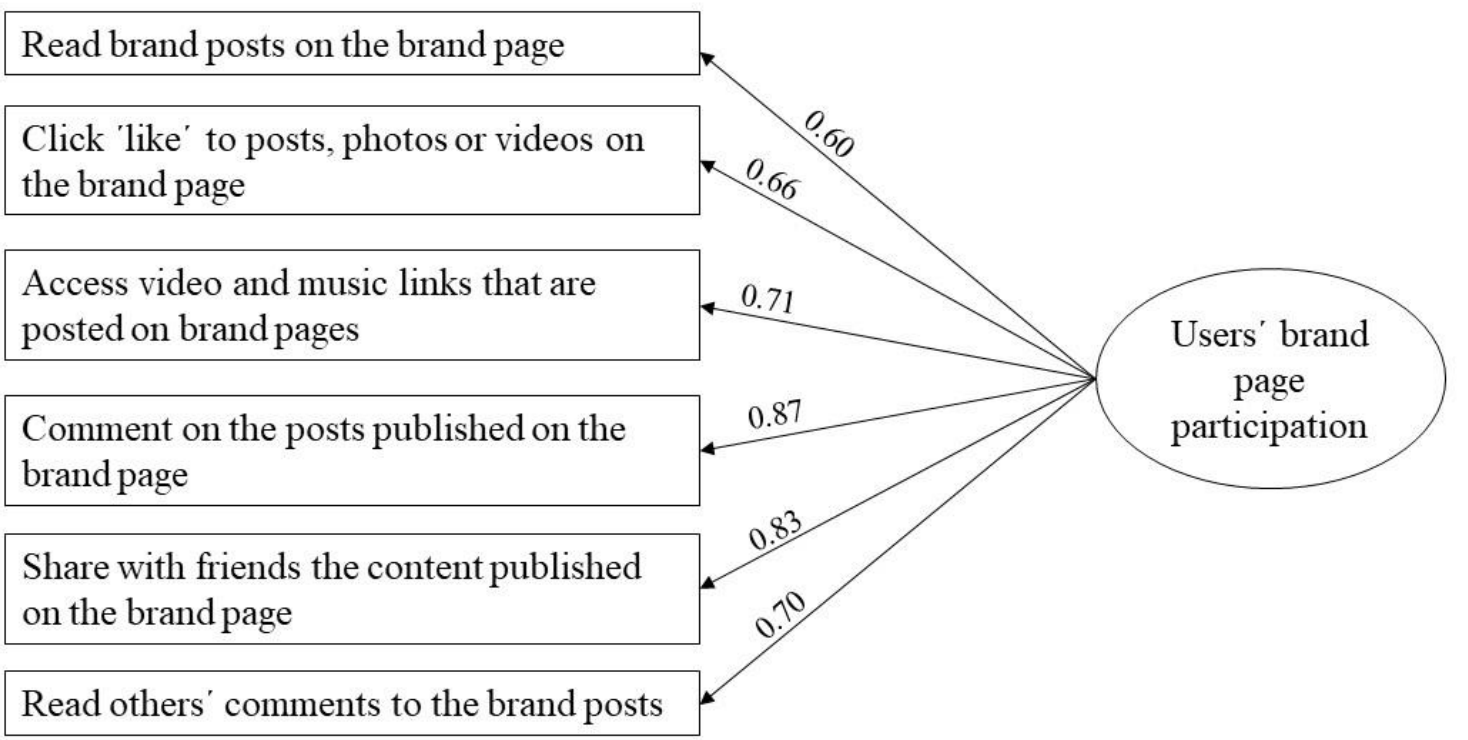

Goodness of fit indices for CFA: $\chi 2=61.5$; df=9; RMSEA $=0.10 ; \mathrm{CFI}=0.98 ; \mathrm{NFI}=0.98$; IFI:0.98; RFI:0,96; GFI:0.95; Estimator: Robust maximum-likelihood; n: 575 ; all standardized coefficients are significant (p-value $<0.001)$. 